\title{
PACE in Europe - delivering for advanced continuing education
}

\author{
Norman Longworth \\ IBM Europe \\ La Hulpe, Belgium
}

\begin{abstract}
The continuing education of European Engineers and Scientists at an advanced level is crucial to the competitiveness and technical vitality of European industry. This paper describes a satellite education delivery facility with terrestrial computer conferencing feedback to provide advanced education from European Centres of Expertise, usually based in Universities, to engineers in industry, at their own workplace.
\end{abstract}

\section{An introduction to PACE}

\section{Why Pace?}

It is estimated that USA Industry spends 40 to 80 billion dollars per year (it is difficult to be precise) on Continuing Education, comparable to all the funds available to public and private universities together. And in a fastchanging technology-oriented world it is easy to guess why. Continuing Education of a nation's engineers, scientists and managers is the only way to maintain their technical vitality and hence the competitive edge which both companies and nations need to survive in that world.

But Continuing Education is expensive, at an advanced level it is in short supply and both the need and the demand for education are growing rapidly. Individual companies do not have the resources to meet the growing needs, which is anyway often difficult to find; in Europe, even 
individual nations have difficulty in supporting education, research and development in all the rapidly advancing technologies.

PACE, as a European education facility, aims to help solve these problems by broadcasting advanced level courses for engineers and scientists via satellite and installing an advanced computer conferencing network to establish feedback and interactivity. This system has several advantages:

- it shares the cost of Continuing Education among receivers;

- it gives access to the best European centres of expertise;

- it enables education to be taken in the workplace, flexibly; and

- it provides motivation for scientists, engineers and managers to update themselves.

\section{The origins of PACE?}

PACE derives its origins from the first Europe/USA Forum on Continuing Education in September 1986, when a group of 50 key European industrialists and academics went to the USA to explore several aspects of the Continuing Education scene there. The use of satellite to deliver Interactive Television (ITV) from University Centres of Excellence to Industry was a particularly attractive feature and the idea of establishing a similar facility in Europe was born.

Five major companies in Europe - Thomson, British Telecom, IBM, Philips and Hewlett-Packard - got together in a cooperative venture to provide the necessary cash, resource and impetus and established a series of Action Groups to give life and direction to the new body. These five have since been joined by seven more sponsors - DEC Europe, Danish Enterprise/University Systems, IRI, FUNDETEC (a Portuguese Consortium), Telefonica, NORIY (a Scandinavian Consortium) and Bull. Thus representatives from companies in Belgium, Holland, France, UK, Italy, Denmark, Portugal, Norway, Sweden, Spain, Finland and Switzerland have given an initial commitment to help launch this unique and necessary program.

The PACE Steering Committee, chaired by Hubert Curien, former French Minister of Research and Technology, also contains representatives of the 
Standing Conference of Rectors, Presidents and Vice-Chancellors of European Universities (CRE), The European Society of Engineering Education (SEFI); observers from COMETT, the European Programme to encourage Continuing Education and Industry/Education cooperation, and DELTA, the European Educational Technology Programme, regularly attend Steering Group meetings.

\section{The many faces of PACE}

PACE has to be seen in three ways:

- firstly, as a delivery system which establishes the technical infrastructure to enable educational supply to meet educational demand through satellite and terrestrial networks;

- secondly, as an educational infrastructure which selects advanced educational topics, identifies European centres of excellence, and uses or commissions courses in those topics from those centres; and

- thirdly, as a financial and promotional organisation which redistributes payment from course receivers to course suppliers, negotiates with Industry, Education and Government for resources to maintain itself and informs and publicises its activities to existing and potential clients and users.

In performing all these functions it is creating and nurturing a European Continuing Education culture which other advanced industrial countries in the world have built up over many years. The benefits of this will extend to:

- industry, in the form of better-educated employees and a sharper competitive edge;

- education, in the wider markets higher education can obtain for its courses, and the challenge of new ideas and methods;

- government, in the greater wealth produced by industry and better informed research departments; and

- individuals, in the better quality and quantity of education available to them. 


\section{The PACE concept}

PACE aims to establish a system to deliver education by satellite from European Centres of Competence to European Industry. Centres of Competence will most often be found in Universities, though PACE also intends to provide seminars and offer courses from other centres of excellence, eg. industry. Universities themselves may also act as course receivers in the PACE structure.

Initially PACE courses will be taped and then distributed within 48 hours. Most will be lectures which would have been given in the normal course of events to a regular audience of students, researchers and/or scientists, and so in the longer run it is expected that there will be a greater incidence of courses delivered in real time.

Feedback will probably take place in four ways:

- In live broadcasts, by direct voice contact to the lecturer, thus offering the student immediate response to questions.

- For all courses, the lecturer will be asked to set aside defined periods of time when he/she can be contacted by telephone, thus offering the opportunity to discuss in more detail.

- For all PACE courses, an advanced computer conferencing facility named PORTAKOM has been installed for student to teacher, and student to student, interaction.

- In addition, course providers $\mathrm{w}$ ill be expected to devise a series of followup materials for individual study and assessment. These will be delivered both by post and by electronic mail through the conferencing system.

Special Events, comprising such occasions as research seminars and conferences, state-of-the-art surveys, and technical press conferences, are also planned.

\section{PACE'S organisational structure}

PACE does not, and will not, employ many people. It has a President, a secretariat and about 15 staff performing promotional, educational, technical, financial and administrative functions. This reflects its essential 
purpose as an educational redistribution channel. However, there are many other whose work and expertise PACE will rely upon. These include the members of the expert groups who will set the content, curriculum and origin of the courses, the members of the Technical, Marketing and Financial committees who have been instrumental in setting up PACE as an organisation and the audio-visual technicians, subject contact points and Steering Committee members in the sponsoring companies who have a1ready invested much time and effort.

PACE will be a non-profit organisation administered by a Board of Trustees. This board will comprise executives from those Companies which are prepared to guarantee for three years payment of the full sponsor membership fee, plus representatives of major European educutional organisations. It will contain a maximum of 20 people and, after a period of four years during the settling-in period of PACE, a plan to encourage new members to serve on the Board will be implemented.

In addition, the Board's educational function will be enhanced by Programme Advisory Groups which contain experts from both industry and education to supervise content, curriculum and educational matters in each of the subject areas and recommend the best course providers.

PACE administration, including the President, Secretariat and Faculty members, will be responsible for negotiating with the many organisations with which PACE must negotiate.

\section{The phases of PACE}

The process of setting up PACE has already begun. After a highly successful Second Europe/USA Forum in Paris, June 1987, at which PACE was launched, major implementation phases were set in place.

- Preparation (July to December 1987) - the full-time secretariat and seconded staff from the sponsors were recruited to prepare for the first PACE broadcasts. Negotiations began with education providers and other groups through the newly set up Programme Advisory Groups, and a Technical Action Group was convened to set up the technical infrastructure which would enable PACE to operate its various video, audio and data networks. In the event the technical task was infinitely less difficult to solve than the many regulatory and procedural protocols which this committee became involved with. At the same time, work went on to establish PACE as a non-profit entity and to find a suitable location for it. 
- Limited Pilot (January to August 1988) - courses and Special Events for a limited experimental audience from sponsoring companies and chosen universities are now being transmitted. This period fulfils three major functions:

- to ensure that the technical infrastructure works, that courses can be delivered and that the feedback mechanisms work;

- to make sure that the level of each course is right for the target audience, of effective video and pedagogical quality, and to learn an acceptable mix of presentational techniques in the new medium; and

- to test out a language strategy which reaches as large a proportion as possible of the audience.

At this moment in time PACE is achieving its objectives in all these areas.

- Full Pilot (September 1988 - August 1989). Planning has of course already commenced for the full pilot phase, in which courses will commence in all the selected topic areas and industry will be invited to register students for these. This is a time when receivers will be paying for their education though not a full price initially. In addition, new strategies will be initiated to attract students from small and medium sized enterprises (SMEs), a particular focus of the European Commission's concern, and to try out ideas concerned with assessment, accreditation and coordination.

- Year One... (from September 1989). In this full courses will be delivered by major European Centres of Competence. Many of these will probably be offered for European accreditation and perhaps degreeawarding.

\section{Membership of PACE}

There are only two categories of membership in PACE

- Full Sponsor - which gives the right to sit on the Board of Trustees and to pay a sponsorship fee of 90,000 ECUs (about A\$160). PACE Full 
Sponsors have the right to influence the direction and curriculum of PACE through membership of all Programme Advisory Groups and to a seat on the Steering Committee and Trustee Board; and

- PACE Client - a company or university which uses PACE services and pays a fee based on the number of sites and students.

\section{The language question}

The multiplicity of European languages is an acknowledged problem. In deciding a language policy three considerations have to be taken into account.

- Firstly, it would be extremely costly to provide a large range of languages.

- Secondly, the language which course providers feel most comfortable with is their own.

- Thirdly, a large majority of European engineers and scientists accept English as a lingua franca for communication and many research papers are written in that language.

Thus, PACE will, by and large, adopt a policy which takes into account these considerations and reaches the majority of engineers and scientists at reasonable cost. Where translation is necessary, simultaneous interpretation, 'voice-over' and 'two-version' techniques may be used as appropriate. Dubbing and sub-titling are both costly and the latter would be unlikely to transfer high level information in adequate quantities. The 'limited pilot' experiments are already giving good feedback in this area.

\section{PACE courses}

There are, of course, many fields of advanced research which PACE could deliver. However, it would be wrong in the early days to become too ambitious in both topic and audience. Consideration has been given to the fact that PACE sponsors are mainly from the information technology industries or have a high information technology component to their operations. Thus the subject areas chosen for the early days of PACE reflect this bias and are shown below: 


\section{PACE FIELDS}

Microelectronics
Expert Systems
Software Engineering
Telecommunications
Technology Management
Advanced Manufacturing Technology

Special themes from these fields are being delivered as both short and longer courses, and also as special events. In addition special events will deal with such additional fields as Superconductivity and other important technological breakthroughs with immediate interest. The latter lectures will be given by the most up to date experts, with supporting materials and systems. PACE courses to date have included the Essentials of Logic Programming from one of the foremost European departments in this field at Imperial College, London, and Functional Languages and Prototyping, from several French research departments at the Sophia Antopolis Research Park near Nice.

\section{Selection of course providers}

Programme Advisory Groups contain experts representing European organisations which have knowledge about the Centres of Competence able to deliver PACE level courses. They take into account the reputation of the centre in its own field and its willingness to back up courses with good materials. Subsidiary parameters include the availability of technical facilities for delivering courses, the translation opportunities existing in the organisation, experience in providing Continuing Education for industry and geographical equity.

\section{A typical PACE course}

A typical PACE Course consists of:

- Video Delivery of lessons from the Centre of Excellence. These may be either live or taped for slightly later delivery.

- Voice Feedback, by telephone. This may be either immediate or at a slightly later time, or both. 
- Follow-up Materials, which take the form of lesson notes, assignments and assessments.

- Computer Conferencing Link for student to teacher interaction, and for delivery of materials.

The length of course varies according to topic and need, but it averages about 20 hours at present, rising to 30 when assignments and feedback through the system are taken into account.

PACE recommends, if possible, an in-company tutoring facility for courses with large numbers of students at the same site, or the use of a local university for follow-up assistance.

\section{Where will PACE fit into a company's education structure?}

PACE is not aimed at the general or basic education market. It is an advanced level Continuing Education facility to keep a company's engineers, scientists and managers at the forefront of technological change in key areas. It will probably not satisfy more than five per cent of a company's educational need, but participation in PACE will be a powerful investment in the ability of European industry to compete in future marketplaces and an opportunity to gain access to an extremely scarce educational resource.

\section{Assessment and accreditation}

Assessment of PACE courses will be carried out by the providing institution. This may be done by a system of feed-back exercises distributed by post or by electronic mail. The receiving organisation will need to supervise this process and to monitor procedures.

It is expected that, in the longer term, such examinations will lead to the award of a credit. The collection of appropriately similar credits will lead to the award of a PACE degree. The exact details of a degree-awarding scheme have yet to be worked out, and it is possible that the European Commission ERASMUS program will provide a focus for work in this area.

\section{PACE finance}

PACE will receive income from two main sources: 
- from Sponsoring Companies in the form of subscriptions and site fees; and

- from Students in the form of course fees. These will usually be paid by the employer.

In addition, the European Commission within the framework of COMETT and possibly other educational programs, has supported PACE. Since PACE had adopted Paris as its location, it will also take advantage of a generous system of local incentives to establish itself and grow.

Additional potential sources of income are national government subsidies, foundations and other European programs, though these are not taken into account in the present financial planning cycle.

Ultimately, it is expected that PACE will be self-supporting by its third year of operation.

\section{Additional costs to industry}

There are some additional costs to the receiving sites. The following outlines some of them, but the actual cost is very dependent on the level of support which each individual company wishes to give to its students:

- Receive Station (downlink);

- Study Centre and furniture;

- Television equipment;

- Videotape equipment, for recording and playback, with possible part time technician support;

- Education Coordinator;

- Workstation (for Computer Conferencing); and

- Line costs for telephone and data.

Guidelines about technical specifications for equipment have been provided well before the first broadcasts, and the ten sites up and running 
at first transmission will have grown to over forty by the end of the Limited Pilot phase. Ultimately of course the receiving sites could be well into four figures in a few years.

\section{A final reflection on PACE to date}

The phrenetic speed at which PACE has been running to set itself up from idea to launch in 9 months and from launch to actuality in a further 9 months - leaves little time for reflection. The everyday firefights take precedence over the long-term dreams. It can be said however that PACE has, so far been a remarkable addition to the European educational scene. This is because of several factors:

- the enormous amount of goodwill it has received from industry, universities and government, particularly the European Commission COMETT project;

- the drive of industry from its twelve sponsoring companies. These have given expertise, cash and a great amount of personnel resources to help set PACE on course;

- the vision of its founding organisations initiated from a glimpse of a similar USA facility and continued through its secretariat and steering committee;

- the determination of its committees, and particularly its technical Action Group, to steer a course through the minefield of European regulations and legislations; and finally

- sheer hard work and, probably, a lot of good luck too.

Author: Norman Longworth M.Phil, MBCS is the European External Education Programs Manager for IBM Europe. He has worked in IBM Education from the United Kingdom, France and Belgium but he has also been to many countries as a consultant and presenter on issues mostly concerned with the implementation of information technology into Education. He has, among many other things, been responsible for setting up and running a 12 million dollar program to make effective use of PCs in schools and vocational colleges, the manager of a DELTA project team to set up a satellite and terrestrial educational network around Europe and, in a former life, a teacher in inner town schools in the North of England. He lists his hobbies as music, tennis, cricket, walking the dog and chronically failing to lose weight.

Please cite as: Longworth, N. (1988). PACE in Europe - delivering for advanced continuing education. Australian Journal of Educational Technology, 4(1), 20-30. http:/ / www.ascilite.org.au / ajet/ ajet4/longworth.html 